\title{
Consistencia y orientación del perfil profesional, percepción del mercado laboral y reacciones previstas ante posibles dificultades de inserción
}

\author{
Helena Troiano \\ Universitat Autònoma de Barcelona. Departament de Sociologia \\ 08193 Bellaterra (Barcelona). Spain \\ helena.troiano@uab.es
}

\section{Resumen}

Este artículo pretende abordar algunos aspectos relacionados con la construcción del rol de estudiante universitario en función de las expectativas, las actitudes, los valores y la orientación hacia la profesión futura. Para ello, se utilizan los datos obtenidos a partir de una investigación sobre el estudiantado universitario a mitad de carrera llevada a cabo en tres regiones europeas: Baden-Württemberg, Rhône-Alpes y Cataluña. En el trabajo, se ponen en relación tres conjuntos de variables: $a$ ) por un lado, contemplamos el perfil profesional que el estudiante se encuentra en proceso de construir; $b$ ) por otro, examinamos su percepción de las oportunidades que le ofrece el mercado laboral, y c) por último, atendemos a la influencia que ambos ejercen sobre la probabilidad de adoptar diferentes estrategias de solución ante posibles dificultades de inserción en el mercado laboral.

Palabras clave: rol de estudiante, estudios universitarios, profesionalización, motivación de los estudiantes, inserción en el mercado laboral.

Abstract. The consistency and orientation of the professional profile, labour market perception and reactions foreseen as regards eventual difficulties of insertion

This paper attempts to examine some aspects related to the construction of the student's role according to his/her expectations, attitudes, values and orientations towards a future profession. To do that, some data gathered in a survey on university students halfway through their studies in three European regions (Baden-Württemberg, Rhône-Alpes and Catalonia) are used. Three sets of variables are put in relation: $a$ ) the professional profile that the student is already building while studying; $b$ ) his/her perceptions regarding the opportunities offered by the labour market; and $c$ ) the influence that the former ( $a$ and $b$ ) have on the possibility of adopting different resolution strategies when facing eventual difficulties to enter the labour market.

Key words: student's role, university studies, professionalisation, students' motivation, labour market insertion. 


\section{Sumario}
1. Introducción
4. Discusión de resultados
2. Perfil profesional e inserción futura
5. Conclusiones
3. Influencia de los valores profesionales
Bibliografía y la percepción del mercado laboral sobre las reacciones previstas ante dificultades de inserción

\section{Introducción}

Las expectativas que los estudiantes universitarios mantienen en relación con la universidad son múltiples y atañen a diversas áreas de funciones y objetivos; asimismo, hace tiempo que la diversidad ha hecho acto de presencia en las instituciones de educación superior, de manera que no podemos considerar al estudiantado como un grupo unitario que evoluciona homogéneamente en una misma dirección, sino que se trata más bien de grupos dispares que presentan expectativas y demandas diferenciadas entre sí (James, 2002).

Ahora bien, a pesar de esta diversificación, se aprecia la tendencia general a que uno de los aspectos fundamentales en la construcción de roles diferenciados entre los estudiantes universitarios sea la prefiguración que éstos realizan de su futura inserción y vida profesionales. Esta dimensión del rol da continuidad y trasciende el período de tiempo estricto de paso por la universidad, y se concreta en la manifestación actual de expectativas futuras.

Es evidente que esta vertiente «económico-profesional» no es más que una función entre muchas otras de las que la universidad se plantea. Con lo cual, cabe esperar que para algunos estudiantes — quizá más frecuentes en algunas áreas concretas - la fuerte priorización de otros aspectos haya relegado esta función al mínimo. Pero, precisamente, el mayor o menor valor que los estudiantes universitarios otorgan a cuestiones relacionadas con su futuro profesional, nos informa sobre las culturas y los roles predominantes entre ellos.

Efectivamente, las funciones manifiestas de la universidad son múltiples, tal y como las explicita Bargel:

[...] la reproducción (en cuanto a investigación) y la transmisión (en cuanto a enseñanza) de una "racionalidad científica» (conocimientos específicos), la «enculturación» general (educación y cultura general), la adaptación económica (experiencia con el mundo y el mercado laboral) y la orientación político-social (participación política e interpretaciones sociales).

Lo importante para la universidad es que estas funciones estén interrelacionadas y que las funciones cultural, profesional y política se mantengan vinculadas a la función principal. (Bargel, 2001)

De esta forma, los miembros e instituciones que forman parte de la universidad, pueden asumir en diverso grado los objetivos, los valores y las normas de cada función, lo que da como resultado una combinación propia en cada caso. 
Igualmente, a lo largo de diferentes períodos históricos, algunas de estas funciones han asumido un papel de mayor protagonismo que las demás. Según Barnett (2000), la tendencia de la universidad actual se dirige a priorizar la acción, el saber hacer, la performativity, todo ello en un intento de responder más eficientemente a la demanda social y económica de profesionalización recibida desde diferentes frentes ${ }^{1}$. Y si tomamos como referente el contexto español de las últimas dos décadas, veremos que no constituye ninguna excepción a esta regla.

Desde la promulgación de la Ley de Reforma Universitaria el 1983, la universidad española se ha visto sometida a una amplia y profunda reforma, una de las claves de la cual ha sido la modificación de los contenidos de los títulos y diplomas existentes, de forma que se aproximen a las demandas del contexto inmediato de la universidad en que se imparten, es decir, relacionar los currículos con el entorno, diferenciarlos de los de otras universidades, ofrecer contenidos más relevantes y adoptar un marco de referencia en el que la profesionalización sea tomada en cuenta (Maravall, 1987; Sánchez, 1996).

Esta tendencia se ha extendido desde el discurso político hasta el discurso público, incluyendo probablemente a los mismos estudiantes y a sus familias. Así que, a pesar de la multifuncionalidad, diversa composición y tradición en diferentes áreas de estudio, vemos que la profesionalización —o inserción, relación con la economía y expectativas futuras - se ha erigido en uno de los aspectos relevantes en el contexto actual (Gallagher, 2002). Es por ello que no parece descabellado prever que tendrá una influencia importante en la construcción del rol y la identidad de los actuales estudiantes universitarios. $\mathrm{O}$, por lo menos, que se habrá reforzado este componente en las áreas con una orientación tradicionalmente más profesionalizadora y habrá asomado en las que históricamente se habían mantenido más alejadas de estos temas.

En este artículo pretendemos, así, identificar la consistencia y orientación del proyecto profesional de los estudiantes universitarios partiendo de los datos correspondientes a una investigación realizada en tres regiones europeas ${ }^{2}$ y a través de una encuesta a 4.029 estudiantes en el momento en que se encuentran a mitad de sus estudios.

Además, intentamos aquí avanzar un poco más allá ya que consideramos que el proyecto profesional puede modificarse a lo largo del tiempo interaccionan-

1. Otra cuestión es que realmente se haya conseguido el objetivo de profesionalizar los estudios enfatizando la vertiente de acción y dejando de lado los otros componentes del currículo. Esta estrategia ha llevado a diseñar planes de estudio, en el mejor de los casos, muy ajustados a los requerimientos laborales específicos en un momento determinado, pero el mismo Barnett, junto con otros autores (Eraut, 1994; Carabaña, 1991), señalan la estrecha vinculación que los estudios tradicionalmente profesionalizadores han establecido entre los conocimientos aplicados, el conocimiento científico y la construcción de identidad profesional, es decir, los otros dos grandes elementos del currículo propuestos por Barnett.

2. Las tres regiones son: Baden-Württemberg, Rhône-Alpes y Cataluña. La investigación se llevó a cabo en el marco de la red Uni21 de la Fédération des Régions d'Europe sur la Recherche en Éducation et Formation (Hadji y otros, 2003; Masjuan y otros, 2003). 
do con otros aspectos, como por ejemplo las percepciones que los estudiantes tengan del mundo laboral, las previsiones de dificultades que realicen, etc.

Para ello, aplicamos un modelo conceptual inicialmente diseñado por Herzberg (1959) para analizar el cambio en contextos de trabajo:

El autor denominó a estos dos factores «Higiene y Motivación» y considera que ambos son percibidos por los individuos como independientes el uno del otro. La higiene se refiere a las condiciones de trabajo, es decir, a cómo los individuos perciben el ambiente de trabajo y la calidad del mismo, y la motivación a la implicación intelectual y emocional con el mismo, es decir a las emociones internas que emergen en los individuos a partir de la realización de un determinado trabajo y que son intrínsecas al mismo. (Masjuan, 2005)

Así pues, nuestra higiene consistirá en la percepción que los estudiantes hayan construido sobre la situación del mercado laboral —en parte fundamentada en las condiciones reales de dicho mercado-, la cual enmarca sus expectativas futuras de inserción. En el apartado 2.2 de este artículo, vamos a examinar la previsión que los estudiantes realizan sobre la naturaleza de su futura inserción, buscando posibles diferencias según área, país, origen social y sexo.

Por otra parte, partimos del presupuesto que la orientación a la profesión es actualmente un componente relativamente importante del rol de estudiante, el cual incorpora progresivamente un cierto ethos profesional durante su paso por la universidad, dando como resultado la construcción de un perfil profesional más o menos consolidado según los casos. Este perfil es el que va a jugar las veces del factor motivación. En el apartado 2.1 veremos la robustez y orientación del perfil profesional de los estudiantes, buscando también divergencias en función de diversas variables independientes. Las mismas que en el apartado 2.3 examinaremos para el repertorio de estrategias preferidas por los estudiantes ante posibles dificultades de inserción en el mercado laboral.

En último término, el apartado 3, pretende explorar la relación que se establece entre las dos categorías anteriores - perfil profesional y perspectivas de inserción - y su peso a la hora de determinar las previsiones que los estudiantes realizan sobre como reaccionarán en caso de encontrarse con dificultades de inserción en el mercado laboral. Entendiendo que esto da cuenta del «grado de flexibilidad [que los estudiantes muestran] en relación con la pérdida de estatus y [otros] inconvenientes, y sus límites» (Bargel, 2001).

Proyecto de perfil profesional: valores profesionales

Percepción de las oportunidades de inserción

Reacciones previstas ante dificultades en el mercado laboral 
La hipótesis se concreta en considerar que las estrategias que los estudiantes anticipan como más probables en caso de encontrarse con dificultades en el mercado laboral, son elegidas desigualmente en función de los valores profesionales predominantes para cada individuo, juntamente con la previsión que haga sobre el tipo y grado de dificultades futuras en su proceso de inserción.

\section{Perfil profesional e inserción futura}

\subsection{Valores profesionales}

En primer lugar, intentamos caracterizar el proyecto profesional que asumen los estudiantes haciendo referencia a qué actitudes y valores priorizan en relación con su futura profesión. Para ello, se les formuló la pregunta «¿Qué es para ti especialmente importante en una profesión?». Los estudiantes debían valorar en una escala de 0 a 6 cada una de las afirmaciones siguientes:

- Trabajar con seres humanos y no sólo con objetos.

- Una ocupación segura.

- Poder realizar las propias ideas.

- Salarios elevados.

- Poder tomar decisiones uno/a mismo/a.

- La posibilidad de dirigir a otras personas.

- Tener tiempo libre.

- Un trabajo que constantemente me imponga nuevos retos.

- La posibilidad de tener una actividad científica.

- Un trabajo que no exija demasiado esfuerzo.

- Ejercer tareas que exijan mucha responsabilidad.

- Poder ayudar a otras personas.

- Tener buenas posibilidades de hacer carrera.

- La posibilidad de explorar lo desconocido.

- Poder hacer algo útil para la colectividad.

- La compatibilidad con la vida familiar.

Con el objetivo de abarcar este conjunto de información, realizamos una agrupación de variables mediante un análisis de componentes principales, a partir del cual extrajimos cinco factores que en total explican el 62\% de la varianza de los 16 indicadores anteriores.

\section{Autonomía}

Este factor se compone de los siguientes indicadores:

- Poder realizar las propias ideas $(0,753)^{3}$

- Poder tomar decisiones uno/a mismo/a $(0,707)$

- Un trabajo que constantemente me imponga nuevos retos $(0,579)$

3. El número entre paréntesis corresponde a una medida de contribución del indicador a la construcción del factor. 
Algunos datos sobre el indicador más representativo de este factor, "posibilidad de realizar las propias ideas», nos podrán dar una idea de las puntuaciones y proporciones que recoge este factor:

Media: 4,9 Desviación: 1,1

Poco importante (0 y 1): $1 \% \quad$ Regular (2, 3 y 4$): 30 \% \quad$ Muy importante (5 y 6): $69 \%$

Este factor viene caracterizado por ser el más relevante entre los estudiantes universitarios. La media del indicador que más contribuye a la construcción del factor es la más alta de todas y, como se puede observar en la distribución, la tendencia a considerarlo «muy importante» es mayoritaria.

La mayor o menor proximidad de los estudiantes a este factor se ha analizado considerando algunas agrupaciones según variables relevantes. A continuación se comentan las diferencias encontradas (figura 1).

La importancia generalizada que atribuyen los estudiantes a este factor se ve reflejada en las menores variaciones que observamos entre titulaciones, e incluso la proximidad entre regiones. Aún así, es estadísticamente significativa esta última diferencia y, por lo tanto, resulta remarcable la tendencia de mayor disposición a la autonomía por parte de los estudiantes alemanes, frente a la menor de los franceses, especialmente en las áreas de Derecho y Salud.

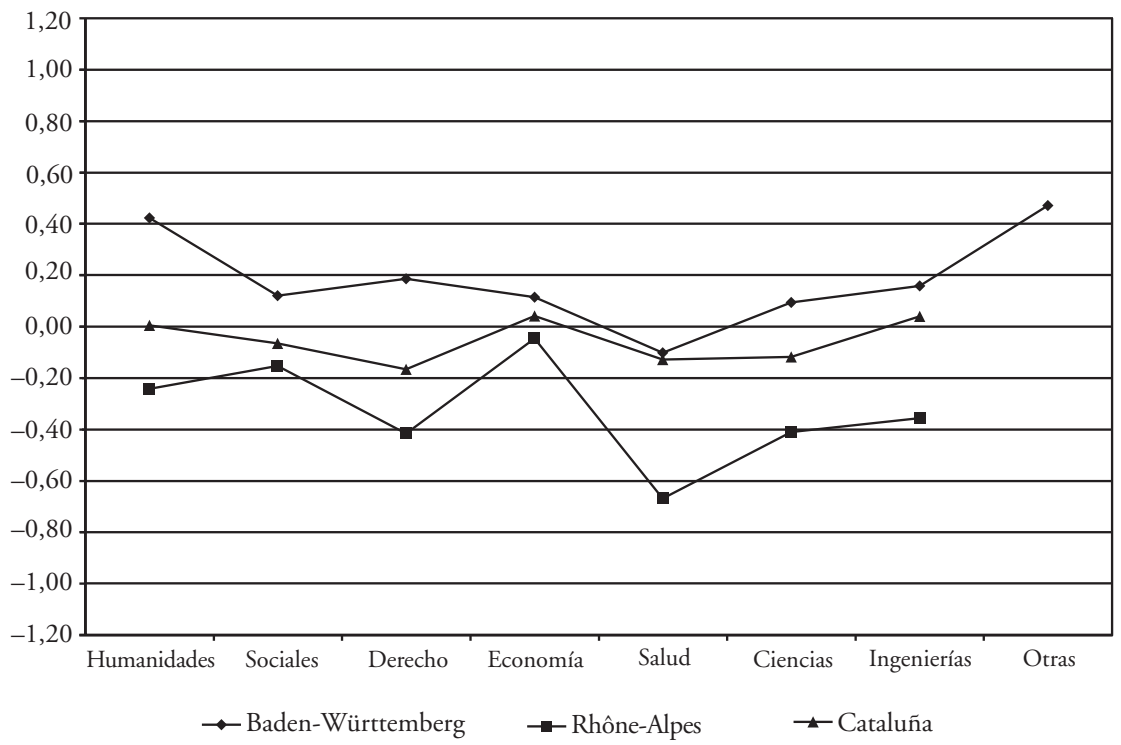

Figura 1. Medidas marginales estimadas: autonomía. 
También se ponen de manifiesto, en el análisis de los datos, las diferencias por origen social: a mayor estatus profesional de padre y madre, mayor valor atribuido a la autonomía en el futuro puesto de trabajo.

\section{Valores sociales}

Se compone de los indicadores siguientes:

- Poder ayudar a otras personas $(0,868)$.

- Poder hacer algo útil para la colectividad $(0,820)$.

- Trabajar con seres humanos y no sólo con objetos $(0,646)$. sonas»:

Descripción del indicador más representativo, «poder ayudar a otras perMedia: 4,5 Desviación: 1,5

Poco importante $(0$ y 1$): 5 \% \quad$ Regular $(2,3$ y 4$): 38 \% \quad$ Muy importante $(5$ y 6): $58 \%$

El de valores sociales es el segundo factor en orden de importancia para los estudiantes entrevistados. En este caso, se han encontrado mayores diferencias que en el anterior comparando entre grupos según variables relevantes.

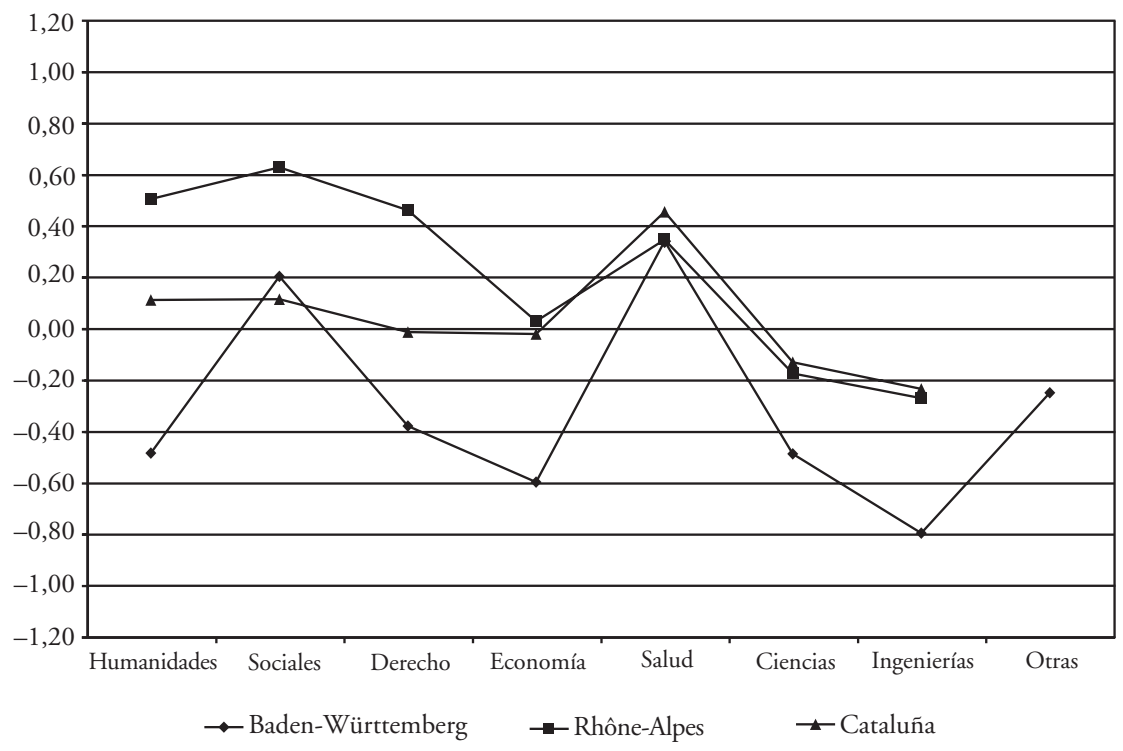

Figura 2. Medidas marginales estimadas: valores sociales. 
Como puede observarse en la figura 2, en la región de Baden-Württemberg es donde los estudiantes se muestran más alejados de estos valores sociales, mientras que en Rhône-Alpes es donde se percibe una mayor inclinación. Ahora bien, las tres regiones coinciden en altas puntuaciones obtenidas por los estudiantes del área de Salud, asimismo, también parece ser un componente importante para el área de Sociales. En cambio, las que otorgan menores puntuaciones son ingeniería, ciencias y económicas.

Resultan muy relevantes las diferencias observadas por sexo: las mujeres son mucho más proclives a valorar estas características relacionadas con valores sociales en su futuro trabajo, mientras que los hombres obtienen puntuaciones mucho menores en este factor.

\section{Ocio y seguridad}

Se compone de los indicadores siguientes:

- Tener tiempo libre $(0,731)$.

- Una ocupación segura $(0,647)$.

- Salarios elevados $(0,625)$.

- Un trabajo que no exija demasiado esfuerzo $(0,570)$.

- La compatibilidad con la vida familiar $(0,476)$.

Descripción del indicador más representativo, «tener tiempo libre»:

Media: 4,3 Desviación: 1,5

Poco importante (0 y 1): $5 \% \quad$ Regular (2, 3 y 4$): 45 \% \quad$ Muy importante (5 y 6): $50 \%$

Como puede observarse, la diferencia semántica del conjunto de indicadores agrupados bajo este factor es muy considerable. Por este motivo, parece oportuno apuntar no sólo la distribución del indicador con mayor peso en el factor, sino algunos datos del resto de indicadores. Así, "Una ocupación segura» presenta una distribución muy parecida a la del indicador principal mostrado; a "La compatibilidad con la vida familiar» le es atribuida mucha más importancia por parte del global de estudiantes, mientras que «Salarios elevados» y, especialmente, "Un trabajo que no exija demasiado esfuerzo» son características poco preferidas por el conjunto de estudiantes.

Tomando esto en consideración, es posible entrever la inteligibilidad de este perfil señalando la consistencia con los valores expresados por los estudiantes en una pregunta más general: para las tres regiones, el aspecto más valorado es la familia de destino, la que se funda o se piensa fundar en un futuro $y$, aunque en diverso orden según la región, los tres siguientes puestos están ocupados por la familia de origen, la «Sociabilidad y círculo de amigos» y el «Ocio y las aficiones».

Las diferencias más significativas observables en este factor nos las ofrecen las variables «Región» y "Área de estudio».

En la combinación que da lugar a este factor, las tendencias diferenciales seguidas en cada país se perciben muy claramente en la figura 3: mientras que 


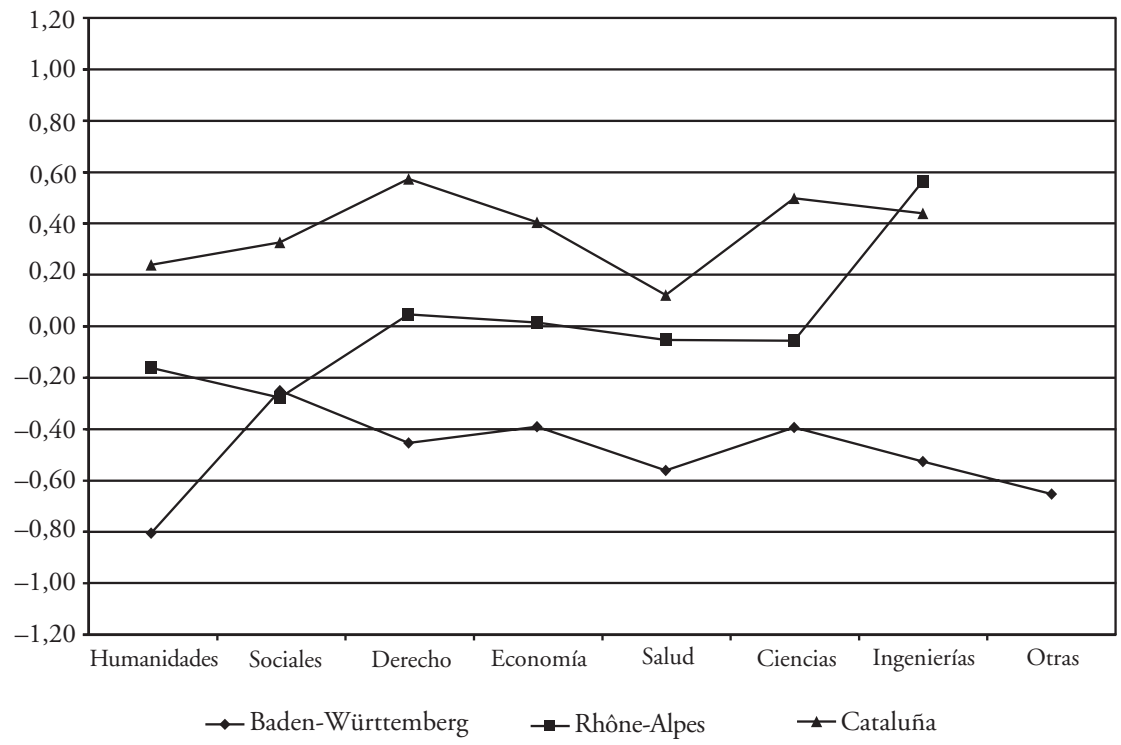

Figura 3. Medidas marginales estimadas: ocio y seguridad.

la región alemana se aleja del valor de ocio y seguridad en el trabajo, los estudiantes catalanes lo suscriben más que el conjunto. Ingeniería resulta ser un área destacada en este factor, especialmente en el caso francés, mientras que las puntuaciones generales de Humanidades son negativas, y mucho más en el caso del área de Salud.

\section{Investigación}

Componen este factor:

- La posibilidad de tener una actividad científica $(0,782)$.

- La posibilidad de explorar lo desconocido $(0,707)$.

El indicador que más contribuye al factor, «La posibilidad de tener una actividad científica», se describe de la siguiente forma:

Media: 3,5 Desviación: 1,8

Poco importante (0 y 1): 17\% Regular (2, 3 y 4): 50\% Muy importante (5 y 6$): 33 \%$

Como se puede observar, la media de puntuaciones en este indicador es más baja que en los casos anteriores y las proporciones de respuesta «Muy importante» también son más escasas. Por tanto, vemos que es una opción menor entre los estudiantes universitarios estudiados. 


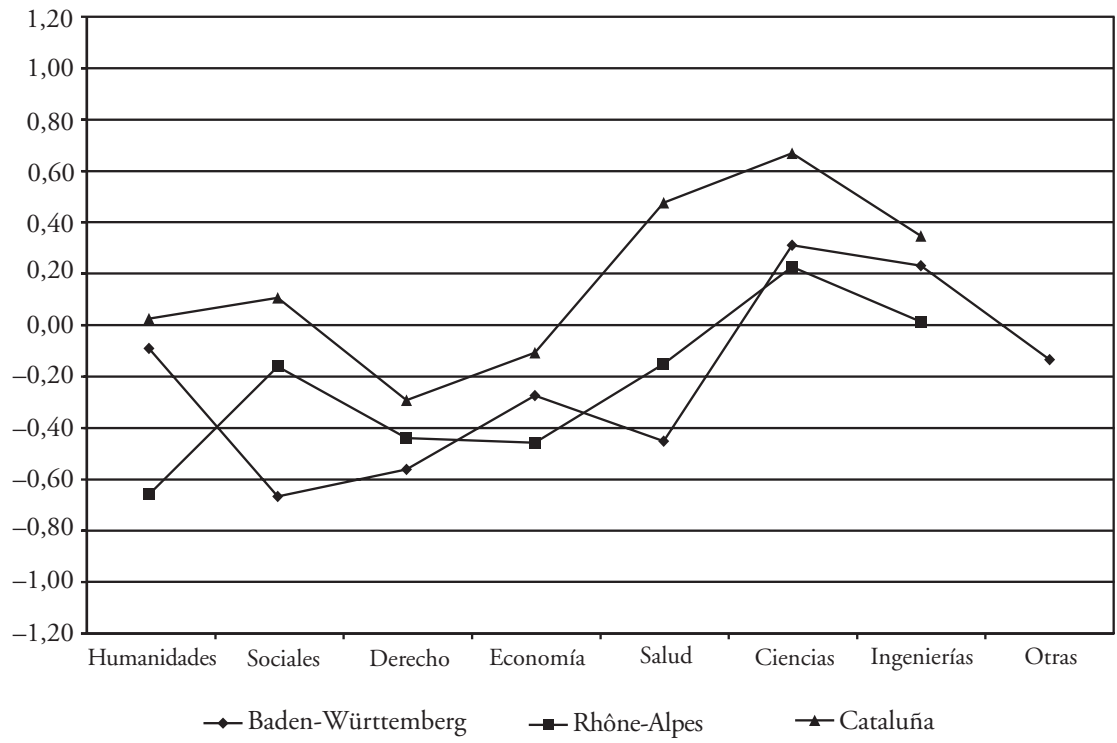

Figura 4. Medidas marginales estimadas: investigación.

Los estudiantes catalanes muestran una mayor inclinación hacia el factor investigación, en todas las áreas, que sus colegas de las otras dos regiones europeas. En los tres países, destacan las áreas de Ciencias e Ingenierías en este factor, pero en Cataluña el área de Salud resulta mostrar tanta o incluso más inclinación hacia esta característica del futuro trabajo - lo cual nos remite al componente científico de este área-, mientras que en las otras dos regiones el área de Salud queda muy alejada.

En los tres países, Derecho se distancia en negativo respecto de este factor, al igual que la de Humanidades en Rhône-Alpes y Sociales en BadenWürttemberg.

\section{Posición de mando}

Los indicadores que lo componen son:

- Posibilidad de dirigir a otras personas $(0,796)$.

- Ejercer tareas que exijan mucha responsabilidad $(0,737)$.

- Tener buenas posibilidades de hacer carrera $(0,622)$.

Descripción del indicador más representativo, «posibilidad de dirigir a otras personas»:

Media: 3,2 Desviación: 1,7

Poco importante (0 y 1): 17\% Regular (2, 3 y 4): 58\% Muy importante (5 у 6): $25 \%$ 


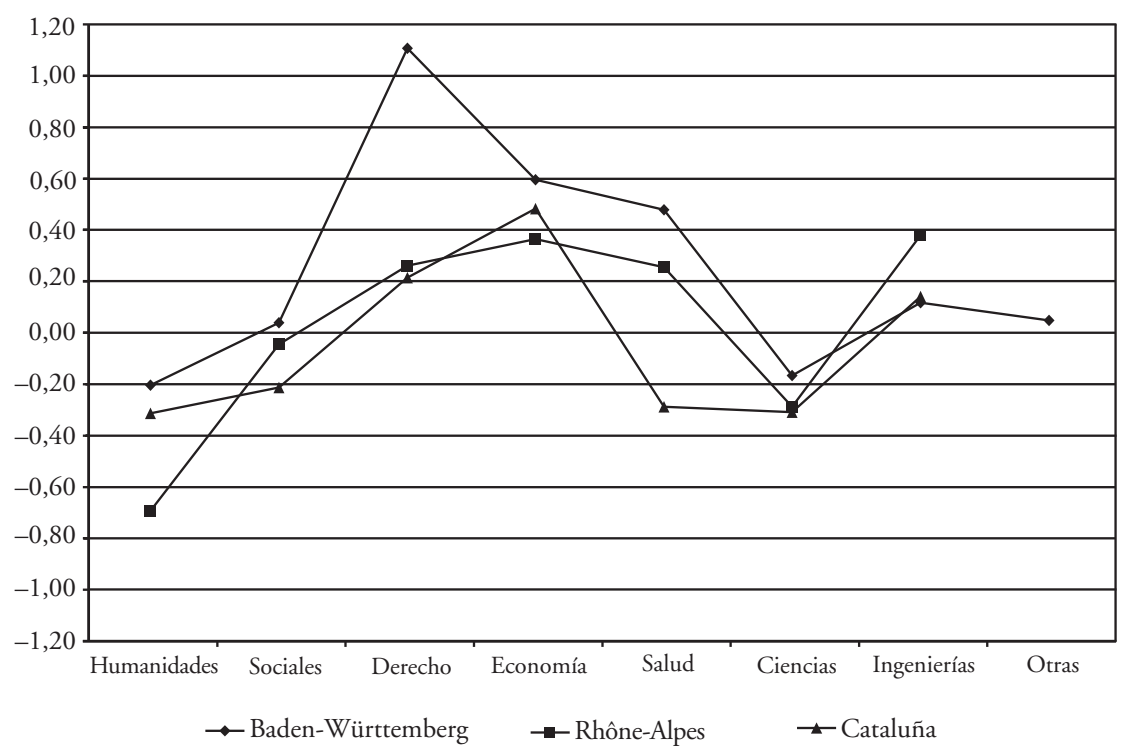

Figura 5. Medidas marginales estimadas: posición de mando.

Nos encontramos ante una preferencia de los estudiantes universitarios todavía menor que en el caso anterior, aunque esto no insta para que se constituya en un factor relevante para distinguir entre regiones y áreas de estudio.

Las áreas más destacadas en este factor son: Derecho, especialmente en la región alemana, Economía e Ingenierías, relativamente destacable pera la región francesa. En el extremo opuesto, las áreas que más se alejan de esta opción son las de Humanidades, Sociales y Ciencias. El caso de Salud merece ser contemplado según el país, puesto que obtiene valores muy dispares en función de la región que consideremos.

En general, las mujeres se muestran menos predispuestas que los hombres a valorar este factor, pero se observan dos excepciones interesantes. Se trata de las estudiantes de Ingenierías y de Humanidades, más dispuestas que sus compañeros a considerar importante la posición de mando y responsabilidad en el trabajo. Lo que hace interesante el caso es el hecho de que la puntuación global de Ingenierías es de las más altas, mientras que Humanidades muestra la más baja de todas las áreas contempladas.

\subsection{Percepción de las oportunidades de inserción}

Examinamos en este apartado la previsión que los estudiantes efectúan sobre las dificultades con que se van a enfrentar a la hora de encontrar trabajo una vez finalizados los estudios. Esta apreciación de más o menos oportunidades se 
recoge a partir de la pregunta "¿Cuál es la situación más probable para ti en cuanto termines los estudios?». Y los estudiantes responden:

- No tendré dificultades para encontrar trabajo 27,8\%.

- Tendré dificultades para encontrar un trabajo que realmente me convenga $35,3 \%$.

- Tendré dificultades para encontrar un trabajo que corresponda a mi formación $20,9 \%$.

- Tendré grandes dificultades para encontrar un trabajo sea cual sea 4,5\%.

- No lo sé $11,5 \%$.

Comparando las tres regiones estudiadas, se observa cómo los estudiantes catalanes son los que realizan una previsión más alta de dificultades en cuanto a la correspondencia entre trabajo y formación $\left(33 / 21^{*}\right)$ y obtienen un porcentaje más bajo por la referencia a ningún problema de inserción $\left(21 / 28^{*}\right)$, mientras que los estudiantes de la región alemana destacan en esta misma categoría $\left(35 / 28^{*}\right)$.

También la diferencia por sexo ha resultado ser significativa. Así, las mujeres $(25 \%)$ prevén más problemas de correspondencia que los hombres $(15 \%)$ y éstos últimos $(36 \%)$ se decantan mucho más por la apreciación de falta de problemas que las mujeres $(22 \%)$.

La diferencia por áreas es fuertemente significativa, pero se trata de una variable que interactúa con la región, con lo que ofrecemos las tablas 1, 2 y 3 , que muestran tales datos a continuación.

De la observación de estas tablas, constatamos, en primer lugar, que efectivamente los estudiantes catalanes prevén mayores dificultades que sus colegas de las otras regiones. Incluso en aquellas áreas en que no quedan por detrás en la categoría "No tendré dificultades» y Rhône-Alpes les toma el relevo -Ciencias, Economía e Ingenierías-, resulta que se trata de áreas en donde

Tabla 1. Baden-Württemberg. Probabilidad de encontrar empleo por áreas. Porcentajes.

\begin{tabular}{llllccc}
\hline & $\begin{array}{c}\text { No tendré } \\
\text { dificultades }\end{array}$ & $\begin{array}{c}\text { Dificultad trabajo } \\
\text { conveniente }\end{array}$ & $\begin{array}{c}\text { Dificultad trabajo } \\
\text { en correspondencia }\end{array}$ & $\begin{array}{c}\text { Grandes } \\
\text { dificultades }\end{array}$ & No lo sé & Total \\
\hline Humanidades & 13,1 & 43,1 & 23,5 & 10,5 & 9,8 & 100 \\
Sociales & 10,2 & 42,9 & 20,4 & 16,3 & 10,2 & 100 \\
Derecho & 11,3 & 56,6 & 3,8 & 11,3 & 17,0 & 100 \\
Economía & 63,6 & 29,3 & 1,4 & 0 & 5,7 & 100 \\
Salud & 21,3 & 59,3 & 6,5 & 9,3 & 3,7 & 100 \\
Ciencias & 38,8 & 38,8 & 10,4 & 5,4 & 6,5 & 100 \\
Ingenierías & 58,2 & 30,1 & 4,1 & 1,4 & 6,2 & 100 \\
Otras & 17,2 & 31,3 & 20,3 & 29,7 & 1,6 & 100 \\
\hline Total & 34,9 & 39,8 & 10,6 & 7,7 & 7,0 & 100 \\
& 340 & 387 & 103 & 75 & 68 & 973 \\
\hline
\end{tabular}


Tabla 2. Rhône-Alpes. Probabilidad de encontrar empleo por áreas. Porcentajes.

\begin{tabular}{llllllr}
\hline & $\begin{array}{c}\text { No tendré } \\
\text { dificultades }\end{array}$ & $\begin{array}{c}\text { Dificultad trabajo } \\
\text { conveniente }\end{array}$ & $\begin{array}{c}\text { Dificultad trabajo } \\
\text { en correspondencia }\end{array}$ & $\begin{array}{l}\text { Grandes } \\
\text { dificultades }\end{array}$ & No lo sé & Total \\
\hline Humanidades & 38,5 & 27,8 & 16,2 & 3,0 & 14,5 & 100 \\
Sociales & 25,5 & 36,3 & 18,1 & 3,9 & 16,2 & 100 \\
Derecho & 20,8 & 50,0 & 10,4 & 3,5 & 15,3 & 100 \\
Economía & 17,3 & 48,8 & 10,2 & 5,5 & 18,1 & 100 \\
Salud & 76,2 & 20,6 & 1,6 & 0 & 1,6 & 100 \\
Ciencias & 27,8 & 39,9 & 13,2 & 1,7 & 17,4 & 100 \\
Ingenierías & 42,8 & 45,5 & 4,8 & 0,7 & 6,2 & 100 \\
\hline Total & 31,9 & 38,8 & 12,4 & 2,7 & 14,3 & 100 \\
& 384 & 467 & 149 & 33 & 172 & 1.205 \\
\hline
\end{tabular}

Tabla 3. Cataluña. Probabilidad de encontrar empleo por áreas. Porcentajes.

\begin{tabular}{llllllr}
\hline & $\begin{array}{c}\text { No tendré } \\
\text { dificultades }\end{array}$ & $\begin{array}{c}\text { Dificultad trabajo } \\
\text { conveniente }\end{array}$ & $\begin{array}{c}\text { Dificultad trabajo } \\
\text { en correspondencia }\end{array}$ & $\begin{array}{c}\text { Grandes } \\
\text { dificultades }\end{array}$ & No lo sé & Total \\
\hline Humanidades & 6,6 & 20,9 & 51,3 & 9,9 & 11,3 & 100 \\
Sociales & 7,5 & 18,9 & 53,2 & 5,0 & 15,4 & 100 \\
Derecho & 9,4 & 32,5 & 35,9 & 5,1 & 17,1 & 100 \\
Economía & 25,5 & 46,6 & 17,4 & 1,9 & 8,7 & 100 \\
Salud & 19,0 & 38,7 & 23,8 & 1,8 & 16,7 & 100 \\
Ciencias & 31,8 & 24,6 & 30,3 & 1,2 & 12,2 & 100 \\
Ingenierías & 44,3 & 39,1 & 7,8 & 2,1 & 6,8 & 100 \\
\hline Total & 21,2 & 30,4 & 32,5 & 3,8 & 12,1 & 100 \\
& 379 & 543 & 579 & 68 & 215 & 1.784 \\
\hline
\end{tabular}

los estudiantes franceses están un poco más preocupados por encontrar trabajos convenientes, pero, aún así, la preocupación de los catalanes recae en la falta de correspondencia con los estudios cursados, indicador de peor calidad del trabajo.

En las áreas de Economía, Ciencias e Ingenierías, los estudiantes de la región alemana perciben una situación del mercado laboral muy optimista, mientras que son los de la región francesa para las áreas de Humanidades, Sociales, Derecho y Salud, los que afirman tener una visión de mayores oportunidades.

\subsection{Reacciones previstas ante dificultades en el mercado laboral}

La elección de una estrategia determinada para afrontar supuestas dificultades de inserción, pone de relieve la voluntad que tiene el estudiante de preservar, a mayor o menor coste, el propio proyecto profesional. 
Esta previsión que los estudiantes realizan respecto de las estrategias más probables que emprenderían en el caso de tener que enfrentarse a dificultades de inserción profesional, pretendemos recogerla a través de la pregunta: «Si a causa de la situación del mercado laboral tuvieras dificultades, después de terminar los estudios, para realizar tu objetivo profesional, ¿de qué manera te comportarías?». Y las respuestas:

- Continuaría estudiando (estudios suplementarios, de profundización o complementarios) para mejorar mis posibilidades profesionales.

- Me quedaría en la universidad para utilizar de forma inteligente este tiempo de espera.

- Aceptaría inconvenientes más importantes (por ejemplo, cambio de domicilio, un trayecto más largo).

- Buscaría alternativas profesionales equivalentes económicamente dentro de mi especialidad.

- Si puedo realizar mi proyecto profesional, aceptaría un sacrificio económico.

- A corto plazo, aceptaría un puesto de trabajo que no correspondiera con mi formación.

- Estaría dispuesto/a a aceptar un puesto de trabajo permanente que no correspondiera a mi formación.

- Intentaría fundar mi propia empresa.

La reducción de esta información mediante un análisis de componentes principales da lugar a cuatro factores que explican el 67\% de la varianza.

\section{Aceptación de no-correspondencia}

Interpretamos que esta opción indica la inclinación más inmediata por parte del estudiante a la pérdida del proyecto profesional. Claro que esto sucede con más intensidad en el caso que se esté dispuesto a elegirla con carácter permanente o sólo temporal, pero ahora veremos que la construcción del factor asocia ambas opciones.

Se compone de los indicadores siguientes:

- Estaría dispuesto/a a aceptar un puesto de trabajo permanente que no correspondiera a mi formación $(0,855)$.

- A corto plazo, aceptaría un puesto de trabajo que no correspondiera con mi formación $(0,832)$.

La distribución de frecuencias del indicador más representativo, «Aceptaría un puesto de trabajo permanente que no se correspondiera con mi formación», es:

Muy poco probable: $34 \%$

Poco probable: $42 \%$

Más bien probable: $18 \%$

Muy probable: $6 \%$ 


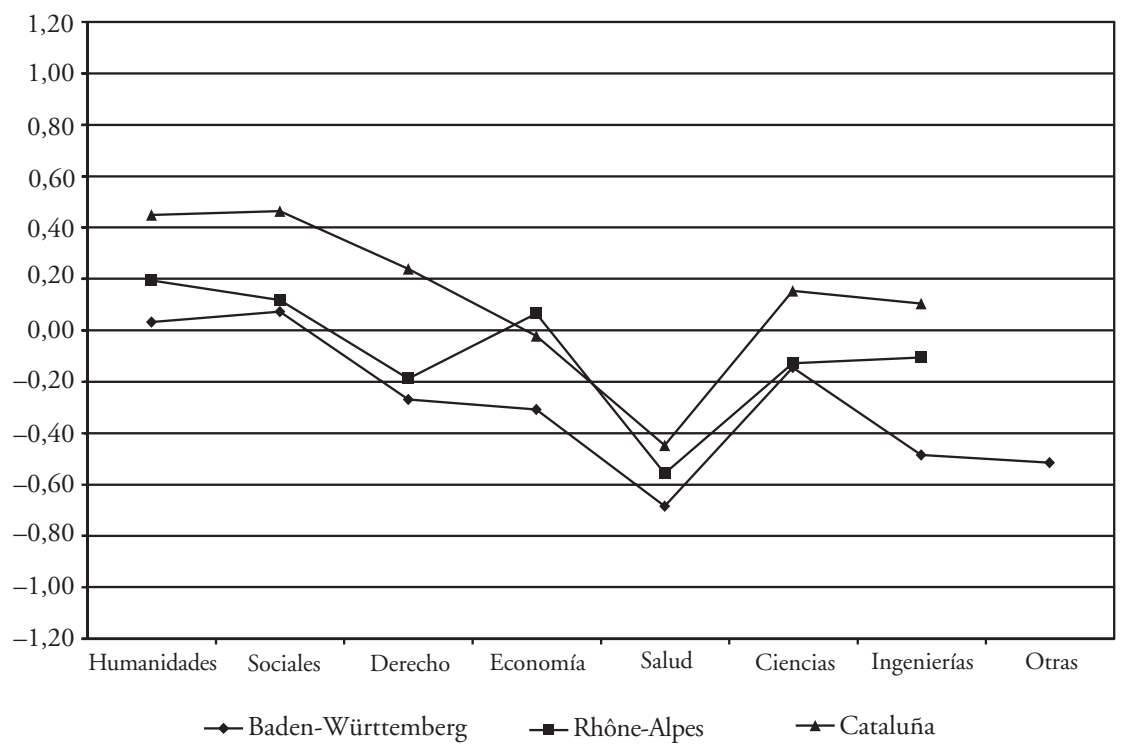

Figura 6. Medidas marginales estimadas: aceptación no correspondencia.

Esta opción es la menos preferida por parte de los estudiantes, con lo que suministra una primera información sobre la importancia que atribuyen a conservar el proyecto profesional que han ido forjando a lo largo de los años.

La región de Baden-Württemberg siempre se mantiene como la más alejada de esta opción, sus puntuaciones son muy parecidas a las de Rhône-Alpes, aunque los estudiantes de Economía de esta última región se escapan de la curva y resultan estar más dispuestos a aceptar puestos de trabajo no correspondientes con su formación. Los estudiantes catalanes, por su parte, casi siempre se mantienen por encima de los demás en este factor.

El área de Salud se caracteriza en los tres países por ser la que más rechaza esta estrategia, lo cual nos remite a la poca aceptación de la pérdida de perfil e identidad profesional extendida en esta área.

Por otro lado, cabe señalar que las mujeres de todas las áreas, excepto Sociales, se muestran más dispuestas a aceptar esta no-correspondencia, especialmente las de Ciencias y Derecho.

\section{Continuación de estudios}

La elección de esta estrategia nos remite a la utilización de los estudios de formación inicial como un tiempo de espera conjugado con el valor defensivo que los estudios tienen en un contexto competitivo. En todo caso, el proyecto profesional no se abandona inmediatamente, sino que se aumentan las opciones laborales aplazando el momento de inserción e incrementando las propias credenciales académicas. 
Los indicadores que forman parte de este factor son:

- Continuaría estudiando (estudios suplementarios, de profundización o complementarios) para mejorar mis posibilidades profesionales $(0,856)$.

- Me quedaría en la universidad para utilizar de forma inteligente este tiempo de espera $(0,833)$.

La distribución de frecuencias del indicador más representativo, «Continuaría estudiando», es:

Muy poco probable: $9 \%$

Poco probable: $21 \%$

Más bien probable: $46 \%$

Muy probable: $24 \%$

Se trata de una de las dos estrategias preferidas por parte de los estudiantes encuestados.

En casi todas las áreas, el factor se comporta de manera que en BadenWürttemberg es donde se opta menos por esta estrategia y en Cataluña es donde más. Las diferencias según área no se muestran estadísticamente significativas.

La variable región está interactuando con la de sexo. Así, resulta que las mujeres alemanas son las que más rechazan la posibilidad de continuar estu-

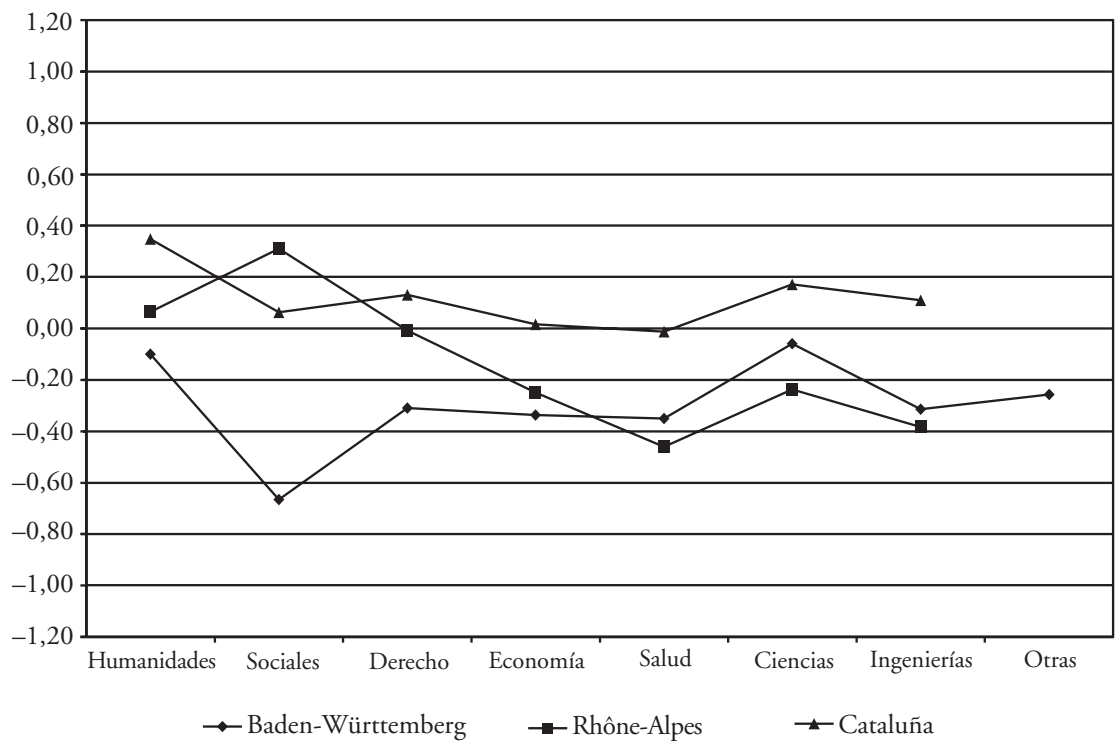

Figura 7. Medidas marginales estimadas: continuación de estudios. 
diando en caso de encontrarse con dificultades de inserción, mientras que las mujeres catalanas son las que más prefieren dicha estrategia.

\section{Aceptación de sacrificios}

Esta opción se traduce en la preservación del propio proyecto profesional, aceptando algún tipo de coste a cambio.

Los indicadores que forman parte del factor son:

- Aceptaría inconvenientes más importantes (por ejemplo, cambio de domicilio, un trayecto más largo) $(0,776)$.

- Si puedo realizar mi proyecto profesional, aceptaría un sacrificio económico $(0,663)$.

- Buscaría alternativas profesionales equivalentes económicamente dentro de mi especialidad $(0,481)$.

La distribución de frecuencias del indicador «aceptaría inconvenientes más importantes»:

Muy poco probable: $6 \%$

Poco probable: $22 \%$

Más bien probable: $49 \%$

Muy probable: $23 \%$

Junto con la estrategia anterior, esta opción es la preferida por los estudiantes que han respondido la encuesta.

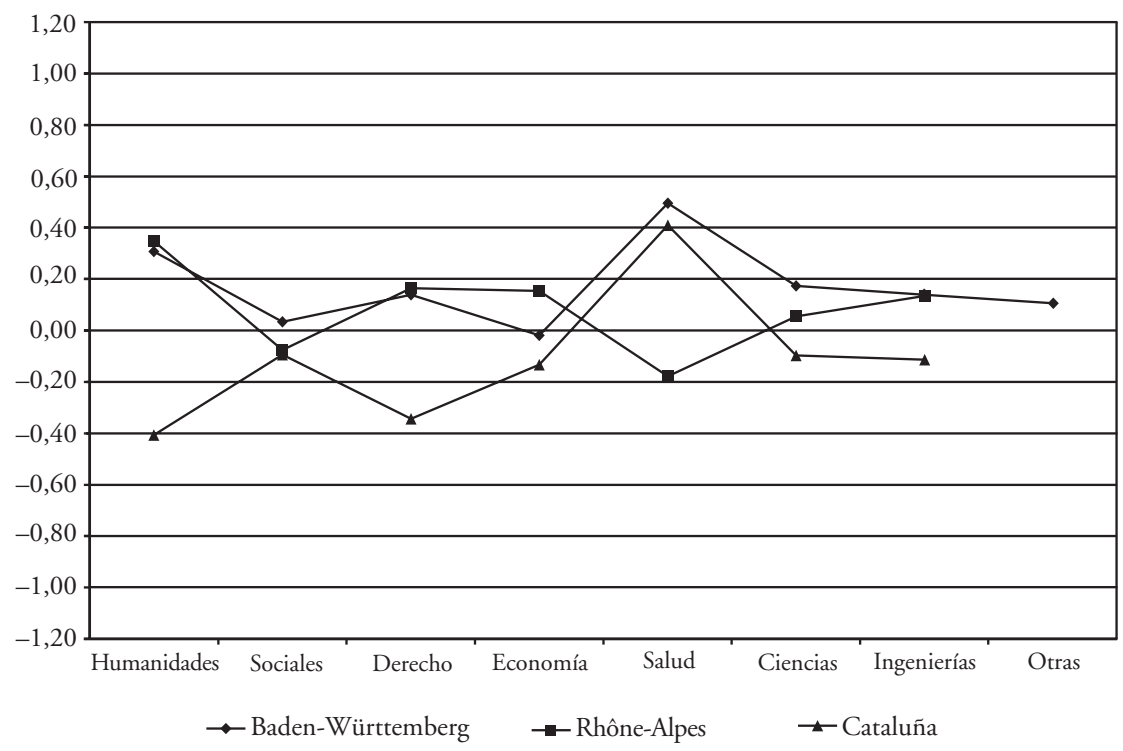

Figura 8. Medidas marginales estimadas: aceptación de sacrificios. 
El área de Salud vuelve a mostrar la priorización que sus estudiantes realizan del proyecto profesional, pero esta vez Rhône-Alpes se desmarca y no acompaña a sus colegas de las otras dos regiones europeas. Igualmente, observamos alguna que otra diferenciación de una sola región para el caso de Humanidades en la región alemana, donde estos estudiantes se muestran más dispuestos a aceptar sacrificios, y también para el caso del área de Derecho en Cataluña, que rechazan la opción de aceptar este tipo de sacrificios.

Además, cabe destacar que las mujeres puntúan en este factor por encima de lo que lo hacen los hombres.

\section{Creación de empresa propia}

En principio, la alternativa de crear una empresa propia no tendría por qué alejar al estudiante de un proyecto profesional vinculado con los estudios cursados, incluso podríamos pensar que se trata precisamente de una alternativa laboral que podría suponer una vía de preservación de tal proyecto.

Un solo indicador se incluye en este factor:

- Intentaría fundar mi propia empresa $(0,897)$.

La respuesta a este indicador se ha distribuido poniendo de manifiesto que se trata de la segunda opción menos preferida de entre todas las propuestas:

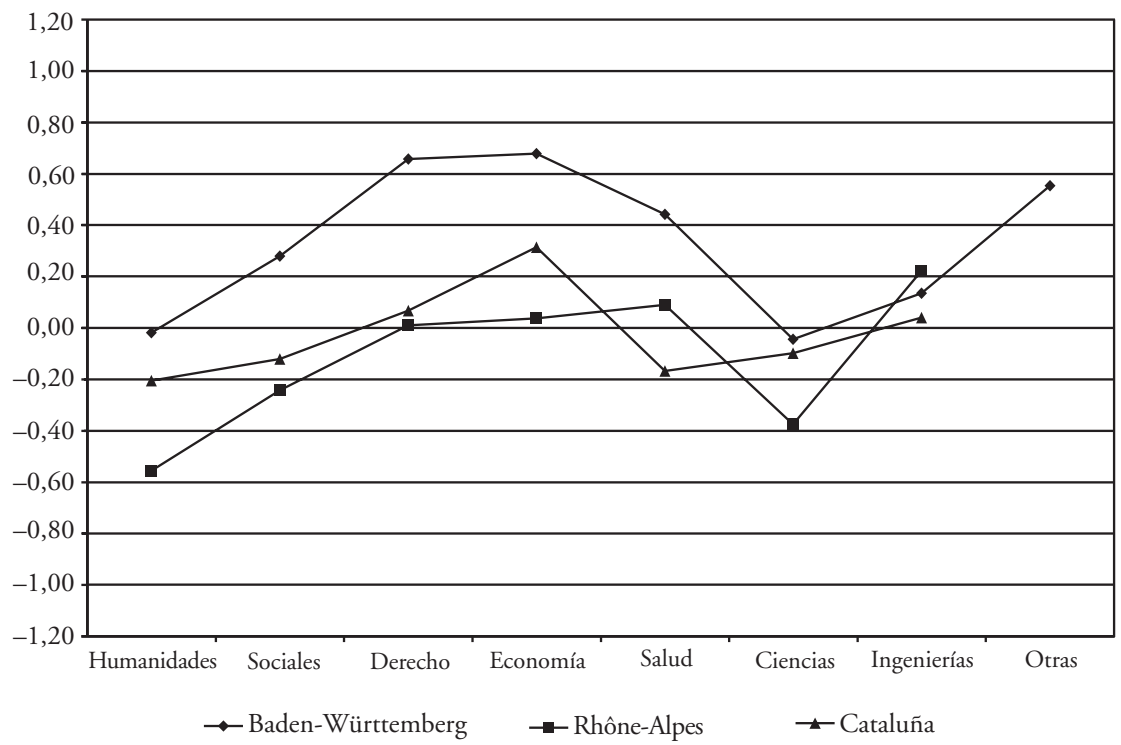

Figura 9. Medidas marginales estimadas: creación de empresa propia. 
Muy poco probable: $37 \%$

Poco probable: $36 \%$

Más bien probable: $20 \%$

Muy probable: $6 \%$

Los estudiantes de Baden-Württemberg puntúan en este factor casi siempre por encima que los de las otras dos regiones, excepto para el caso de ingenierías, donde en las tres es positiva. Las áreas más partidarias de esta estrategia son las de Economía y Derecho, pero hay que destacar que los estudiantes de la región alemana lo son mucho más que el resto. En el polo opuesto, encontramos las áreas de Humanidades y Ciencias, las cuales se alejan de esta opción, en todos los países, pero especialmente en la región francesa.

Esta vez son los hombres los que muestran puntuaciones significativamente superiores a las de las mujeres.

\section{Influencia de los valores profesionales y la percepción del mercado laboral sobre las reacciones previstas ante dificultades de inserción}

Tal y como ya se ha señalado anteriormente, el objetivo de este artículo es el de establecer las relaciones pertinentes entre tres grandes elementos muy vinculados con la construcción del rol de estudiante, aunque sobre la base de sus previsiones y expectativas sobre el futuro: el perfil profesional proyectado, la percepción de las oportunidades de inserción y la influencia de ambas en las reacciones previstas ante posibles dificultades en el mercado laboral.

Las estrategias consideradas dan cuenta de diversas disposiciones de los estudiantes en torno a su futuro trabajo. Así, por ejemplo, las previsiones de posible pérdida de estatus, de aceptación de mayores inconvenientes a cambio de la preservación del proyecto profesional o, al contrario, de pérdida del perfil proyectado — quizá renunciando a determinados valores profesionales previamente asumidos-, señalan las áreas en que los estudiantes se muestran más flexibles y en qué umbrales establecen los límites de sus renuncias. Igualmente, cuando se anticipan estrategias relacionadas con la formación, ampliación o especialización de estudios, el autoempleo, o creación de empresa, se nos remite al acceso y a la puesta en marcha de otros recursos disponibles.

Por otro lado, los valores profesionales descritos para cada colectivo caracterizan a los estudiantes desde la perspectiva de la robustez y dirección que adopta su perfil profesional. Asimismo, la percepción que tienen los estudiantes de la situación del mercado les hace anticiparse al tipo de dificultades con las que se van a encontrar cuando, efectivamente, finalicen sus estudios. La conjunción entre las disposiciones personales respecto del trabajo, junto con la información recibida desde el exterior (aunque interpretada personalmente), pensamos que puede contribuir a que unas estrategias sean más probables que otras.

Con el fin de explorar tales diferencias y relaciones, y contrastar la hipótesis planteada, hemos utilizado las variables descritas hasta el momento: los fac- 
tores resultantes del análisis de componentes principales sobre los valores profesionales ${ }^{4}$, la variable de percepción de las oportunidades de inserción ${ }^{5}$ y los factores surgidos del análisis de componentes principales sobre las reacciones previstas ante dificultades en el mercado laboral ${ }^{6}$.

\section{Aceptación de no-correspondencia}

De entre las estrategias posibles que los estudiantes prevén adoptar en el caso de encontrarse con dificultades en el mercado laboral, la de aceptar un trabajo que no corresponda con la formación universitaria recibida es la que más claramente remite al abandono de las expectativas laborales dentro de una identidad profesional particular.

En cuanto a los resultados, la simple observación del gráfico 10 nos indica que la variable de percepción sobre el mercado laboral está actuando de manera fuerte sobre las estrategias previstas, ya que las líneas se extienden conservando cierta distancia entre ellas.

En efecto, la estrategia de aceptar un trabajo que no se corresponda con los estudios cursados presenta una incidencia de cómo los estudiantes perciben el mercado muy superior al resto de reacciones previstas. Los que de forma más clara rechazan esta posibilidad son los que prevén que no tendrán demasiadas dificultades en su futura inserción, seguidos de cerca $-\mathrm{y}$ mostrando tendencias paralelas - por el grupo de estudiantes que prevé un tipo de dificultad menor, la de encontrar un trabajo realmente conveniente. En el lado opuesto, se sitúan los estudiantes que anticipan situaciones mucho más duras: los que o bien piensan que será difícil encontrar trabajos que correspondan a los estudios cursados, o bien que encontrar cualquier trabajo les comportará grandes dificultades.

Por otro lado, la disposición en diferentes alturas de los puntos en el gráfico según los valores profesionales de los estudiantes deja entrever una cierta influencia de esta variable sobre las reacciones previstas, pero cabe decir que, en realidad, el único valor profesional que se ha mostrado estadísticamente significativo es el de ocio: el grupo de estudiantes en el que este valor está presente se muestra siempre mucho más dispuesto — dentro de cada titulación y de cada visión

4. Los resultados de este ACP se han utilizado para construir cinco variables de carácter nominal: a los estudiantes que puntúan por encima de 0 en un factor, se les atribuye la categoría que indica la presencia del valor, mientras que a los que muestran una puntuación negativa, en la nueva variable se indica la ausencia del valor.

5. Esta variable se ha utilizado conservando el mismo formato, sólo que en las proyecciones de gráficos, con el fin de alcanzar una mayor claridad en la exposición de resultados, se ha omitido la categoría «No lo sé».

6. Tales factores se conservan como variables estandarizadas. Éstas últimas se consideran variables dependientes de las dos anteriores, que son tomadas como variables independientes en los modelos de análisis de varianza (ANOVA). El área de estudio se ha añadido como variable de control, puesto que durante todo el estudio se ha revelado como variable explicativa muy importante. 


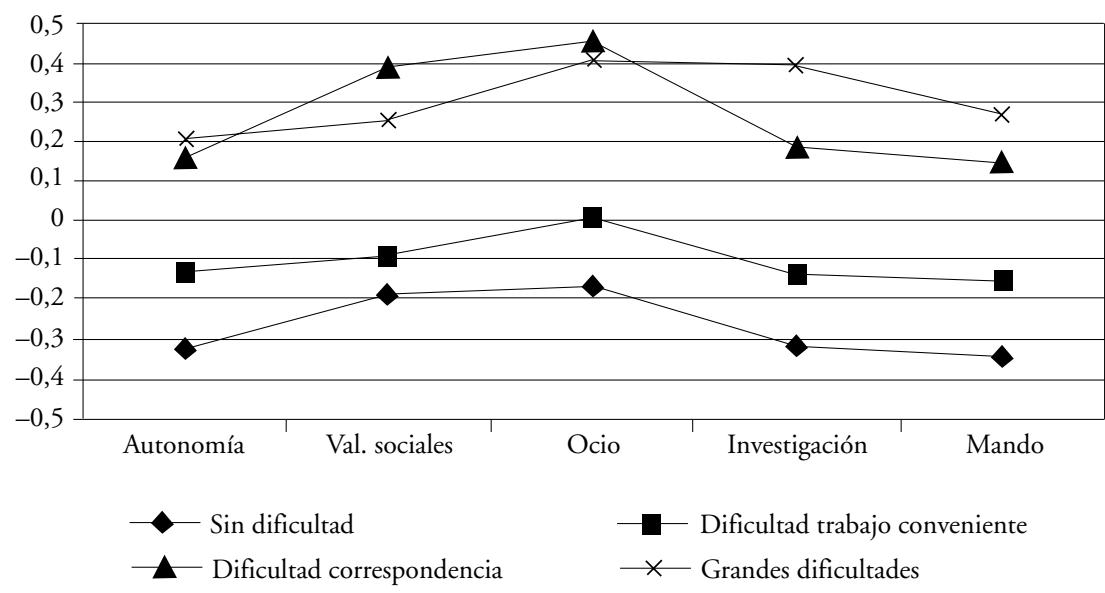

Figura 10. Aceptación no-correspondencia.

sobre el mercado laboral - a asumir la pérdida de identidad profesional que supone la aceptación de un trabajo en no correspondencia con los estudios cursados.

La influencia del resto de valores profesionales que se observa en el gráfico se produce debido a su estrecha relación con el área de estudio. Ahora bien, también se han puesto de manifiesto algunas excepciones interesantes. Por ejemplo, los estudiantes de Economía tienden a rechazar esta estrategia, pero si además asumen valores de autonomía o de mando, resulta que aún la desestiman más que sus compañeros dentro de la misma área. Otro ejemplo interesente se localiza en el área de Sociales, donde los estudiantes que presentan valores de investigación se muestran más dispuestos a aceptar trabajos en no correspondencia con los estudios cursados, lo cual quizá nos da pistas sobre la indefinición del perfil profesional como ocupación específica cuando el interés principal recae en la actividad investigadora.

\section{Continuación de estudios}

La estrategia de prolongar el período de formación en la universidad o a través de otro tipo de ampliación de estudios, especialización, etc., se constituye en una alternativa que apuesta por aprovechar pacientemente el compás de espera, abasteciéndose de más recursos para afrontar con mayores garantías las posibles dificultades de inserción futuras.

Como puede observarse, las líneas que representan diversas percepciones de la situación del mercado se muestran mucho más juntas que en el caso anterior, lo que ya adelanta que la relación entre las variables resultará ser no significativa. A pesar de ello, cabe destacar la mayor adopción de esta estrategia por 


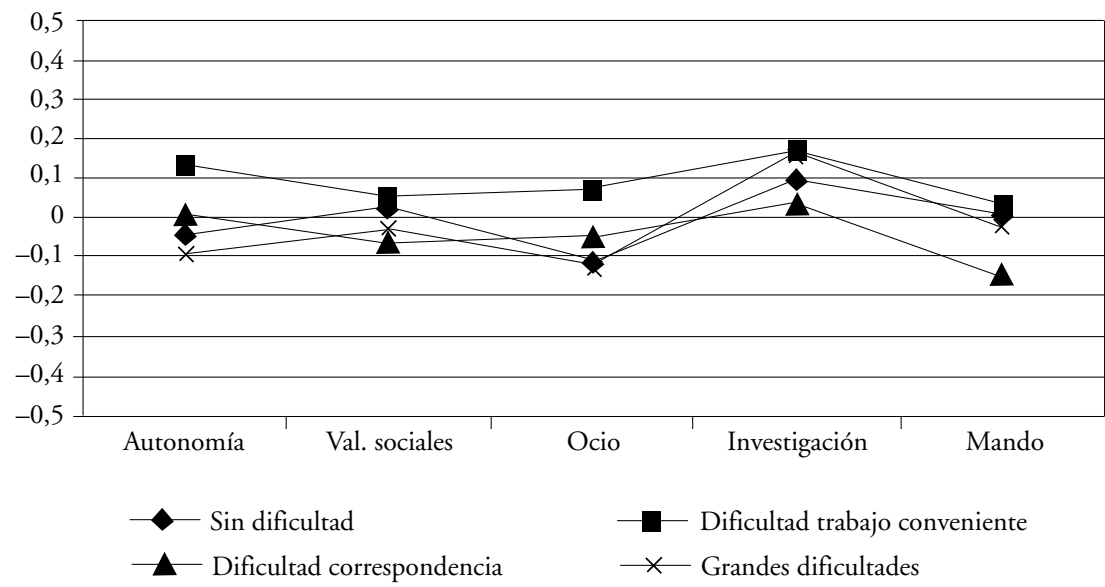

Figura 11. Continuación de estudios.

parte de los que prevén dificultades en el acceso a un trabajo conveniente y asumen valores de ocio y de autonomía.

$\mathrm{El}$ área vuelve a ser la variable independiente más importante, lo cual se traduce en valores profesionales que puntúan de forma diferente en la estrategia. Sólo en tres casos los valores cobran relevancia por ellos mismos; presentados de forma creciente según su peso en la relación:

- Valores sociales: Dentro de cada área, los estudiantes que presentan valores sociales, se muestran más dispuestos a adoptar la estrategia de continuar estudios ante posibles dificultades. Las áreas que más destacan en esta tendencia son Ciencias, Humanidades, Sociales y Derecho, ésta última presenta mucha distancia entre los estudiantes que asumen el valor y los que no.

- Autonomía: Los estudiantes que asumen el valor de autonomía seguirían más esta estrategia, especialmente los que prevén dificultades en el acceso a un trabajo conveniente. En las áreas de Ciencias, Salud y Derecho los que sí presentan el valor de autonomía se destacan mucho de los que no lo hacen.

- Investigación: Como ya puede observarse ligeramente en el gráfico, los estudiantes con el valor de investigación son los que más seguirían esta estrategia. Y dentro de cada área también son los que se distancian más de sus compañeros sin este valor profesional, especialmente en Ingeniería, Salud, Ciencias y Economía. 


\section{Aceptación de sacrificios}

Los sacrificios económicos o bien otro tipo de inconvenientes (desplazamientos largos, cambios de domicilio, etc.) son el precio que esta estrategia se cobra a cambio de poder elegir ocupación y desarrollar el proyecto profesional gestado a lo largo de los años.

Una vez más, la variable área adquiere cierto protagonismo al presentarse como la variable con influencia más constante a la hora de predecir esta estrategia, aunque a menudo se presenta interactuando con la percepción que los estudiantes tienen del mercado laboral.

Por otra parte, como en el caso anterior, sólo tres de los cinco valores profesionales muestran su influencia. En primer lugar, la presencia del valor profesional ocio permite predecir una menor aceptación de sacrificios como reacción ante las dificultades de inserción, y esta tendencia funciona también en general dentro de cada titulación. En segundo lugar, los que asumen el valor profesional autonomía aceptarían esta estrategia en mayor medida que los que no lo hacen; y se mantiene la relación dentro de cada área excepto en Salud, donde la aceptación de sacrificios es superior al resto de áreas, sin que se presenten diferencias entre los que muestran el valor autonomía y los que no. Por último, en el valor investigación, como en el de autonomía, aceptarían más los trabajos que comportaran sacrificios; sin embargo, cuando observamos los datos por áreas, vemos que sólo se perciben diferencias significativas en las áreas de Derecho y Salud.

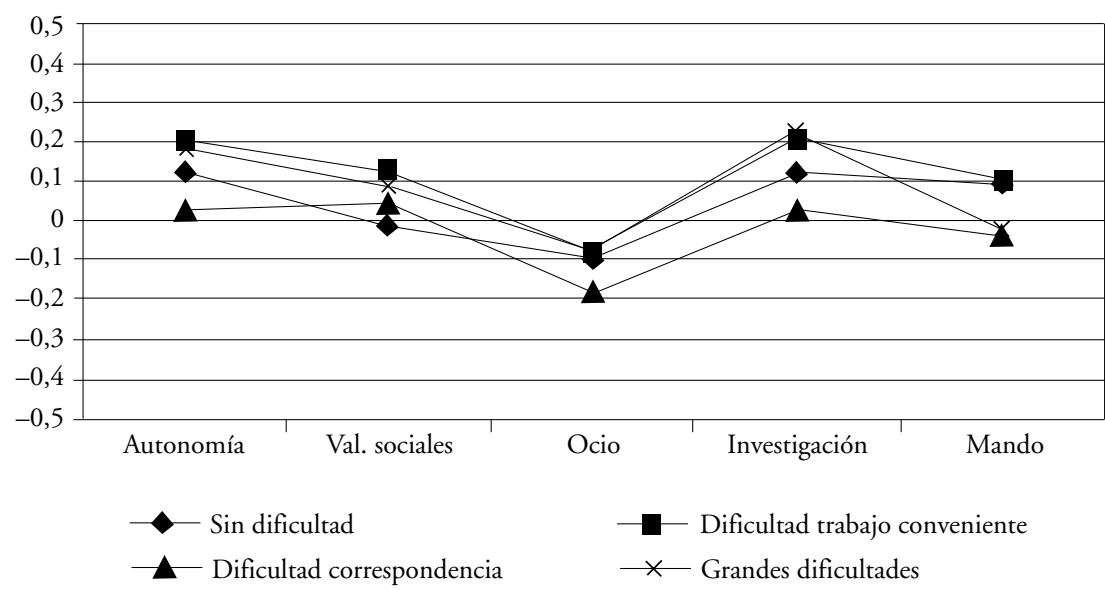

Figura 12. Aceptación de sacrificios. 


\section{Creación de empresa propia}

Reaccionar ante posibles dificultades de inserción creando la propia empresa es una alternativa que denota una cierta disposición a adoptar una actitud activa por parte de los estudiantes que la suscriben. Y ello porque, a pesar de que en los estudios de inserción la posición de autoempleo puede interpretarse en muchos casos como indicador de precariedad laboral — debido al fenómeno del establecimiento por cuenta propia trabajando como empleado «externo" de una sola empresa-, no es probable que las previsiones que realizan los que todavía son estudiantes se refieran a esta opción. Es mucho más probable que la preferencia mostrada por crear una empresa propia refleje una actitud más propensa a la búsqueda real de autonomía en el mercado.

Esta asociación de la opción con actitudes en general más bien optimistas se observa en el gráfico a primera vista, donde queda claro que los estudiantes que prevén pocas dificultades de inserción ${ }^{7}$ siempre se muestran más predispuestos que el resto de estudiantes a aventurarse en esta alternativa.

La variable de valores profesionales actúa como predictora de la adopción de esta estrategia en forma clara, excepto para el caso del valor ocio. Repasemos, pues, cada uno de los valores en relación con las otras dos variables:

- Valores sociales: Los estudiantes que muestran valores sociales rechazan mucho la posibilidad de crear una empresa y alcanzan una gran diferencia para el caso de los que prevén encontrar dificultades de correspondencia en el mercado. Esta gran distancia entre los que poseen el valor y los que no, se mantiene dentro de cada área excepto en Derecho y Ciencias, áreas en las que poseer o no valor social no incide en la mayor o menor predisposición a fundar una empresa; simplemente, en Derecho hay más tendencia a optar por esta alternativa y en Ciencias a rechazarla.

- Mando: Los estudiantes que se inscriben en este valor tenderían a crear una empresa prescindiendo bastante de la visión que tengan sobre la situación del mercado laboral, excepto por el hecho de que los que anticipan pocas dificultades de inserción muestran una preferencia todavía un poco mayor por la posibilidad de fundar una empresa propia. Dentro de cada área, también se percibe esta mayor tendencia a crear empresa por parte de los que muestran el valor mando, lo cual se hace especialmente importante en las áreas de Ingeniería, Derecho y Economía.

- Autonomía: Los que poseen el valor autonomía también aceptarían esta opción por encima de los que no lo poseen, especialmente si prevén pocas dificultades de inserción, pero casi sin mostrar diferencias si anticipan difi-

7. Nótese que se pide a los estudiantes que elijan una estrategia suponiendo que se encontrarán efectivamente con dificultades de inserción, no se les pide que hagan una previsión sobre la posibilidad de crear una empresa en las condiciones que creen que van a encontrarse; a pesar de ello, parecen haber respondido quizá sin acabar de creerse la situación. 


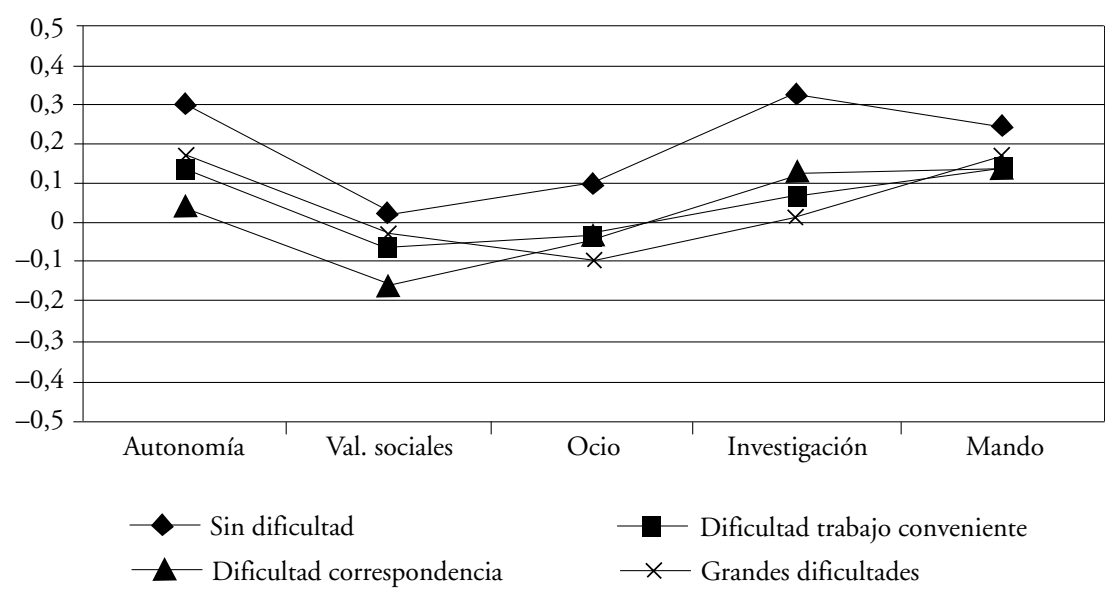

Figura 13. Creación de empresa propia.

cultades de correspondencia. Dentro de las áreas, se mantiene siempre la diferencia a favor de los que poseen el valor, y ésta se hace especialmente relevante en Derecho e Ingeniería, donde, como en Economía, los estudiantes se muestran muy dispuestos a reaccionar ante el mercado fundando una empresa.

- Investigación: Como en el caso anterior, los que poseen el valor investigación, se muestran más dispuestos a crear una empresa que los que no muestran el valor, especialmente cuando creen que tendrán pocas dificultades en el mercado laboral. Ahora bien, se diferencia de los resultados obtenidos en el valor autonomía por el hecho de que, en este caso, cuando los estudiantes creen que van a toparse con dificultades a la hora de encontrar un trabajo que corresponda a los estudios cursados, reaccionan favoreciendo de forma importante la creación de empresa propia. También para este valor encontramos la particularidad de que dentro de cada titulación los que poseen el valor y los que no, se sitúan a poca distancia, aunque siempre a favor de los primeros.

\section{Discusión de resultados}

Tal y como hemos visto en el apartado anterior, el objeto del trabajo exploratorio de este artículo (esto es, la relación entre las variables profesionales y la percepción del mercado laboral que influyen en las reacciones previstas ante dificultades de inserción) se ha mostrado relevante sólo en algunos casos. Si recuperamos y resumimos los hallazgos encontrados, podemos establecer, en 
primer lugar, que la percepción que los estudiantes tienen de la situación del mercado laboral afecta en gran medida a la adopción de la estrategia de aceptar un trabajo que no se corresponda con los estudios cursados; y sólo la categoría de los que no prevén dificultades de inserción influye en la estrategia de crear una empresa propia. Además, tanto en éstas como en alguna otra relación, vemos que se trata de una variable que tiende a interactuar con alguno de los valores profesionales contemplados.

En segundo lugar, la variable que nos acerca a la consolidación y orientación del perfil profesional, los valores profesionales, ha manifestado su importancia como predictora de las reacciones que los estudiantes piensan adoptar ante dificultades en el mercado laboral; aún así, a menudo resulta que la variable que realmente está desenvolviendo el papel de variable independiente es el área de estudio. Parece ser que ésta última define bastante lo que dentro del colectivo específico se considera aceptable (o quizá simplemente viable) como salida ante una situación laboral adversa. En general, hemos visto en los apartados más descriptivos que la caracterización del área a partir de éstas (y otras) variables permite apreciar un grado importante de homogeneidad interna en cada área y de diferenciación externa respecto del resto de áreas, incluso más allá de las fronteras de las tres regiones, aunque también en alguna ocasión las tradiciones diversas en los tres países han tomado mayor protagonismo, diferenciando una misma área según la región de pertenencia.

Examinemos ahora este conjunto de relaciones repasando con cierto detalle los resultados obtenidos.

\section{a) Aceptación de no-correspondencia}

- Positivo: grandes dificultades, dificultades de correspondencia; ocio; investigación-Sociales.

- Negativo: dificultades trabajo conveniente, sin dificultades; MandoEconomía, Autonomía-Economía.

Ya se ha señalado que la estrategia de aceptar un trabajo que no corresponda con los estudios supone un abandono claro del perfil profesional proyectado, aunque también podría remitir precisamente a la inexistencia de tal perfil. Sea como fuere, el hecho de que esta estrategia sea la menos elegida, contribuye a corroborar la hipótesis de que el proyecto profesional es algo extendido entre los estudiantes universitarios y que le atribuyen bastante importancia.

Esta tendencia se ve fuertemente acentuada para los estudiantes del área de Economía con valores profesionales de autonomía y de mando, lo cual puede que constituya un buen indicador de su posición asertiva ante el mercado laboral.

Ahora bien, en algunas situaciones la tendencia se invierte y los estudiantes se muestran más inclinados a adoptar esta opción de no-correspondencia. Primero, cuando su percepción sobre la situación del mercado laboral es fran- 
camente pesimista, quizá como último recurso ante tanta fatalidad. Segundo, cuando sus valores profesionales destacan en los aspectos que hemos recogido bajo el epígrafe de "ocio», siguiendo coherentemente un talante según el cual lo menos importante es el contenido del trabajo y lo más importante, precisamente, es lo que permite hacer fuera, dejando tiempo libre disponible y seguridad para vivirlo bien. Tercero, para el área de Sociales, cuando el valor profesional predominante es el de investigación, y aquí no se nos ocurre más que apelar a la posible indefinición del perfil profesional en esta situación, dentro de un área donde el ejercicio de una profesión ya se encuentra a menudo desdibujada.

\section{b) Continuación de estudios}

- Positivo: valores sociales, autonomía, investigación; autonomía-dificultad trabajo conveniente.

Interpretar las relaciones que se establecen entre la estrategia de continuar estudiando y las variables que son objeto de estudio en esta exploración, comporta un cierto riesgo, debido a que, como ocurre con la propia estrategia, algunas de las variables que se han mostrado más relevantes (el valor profesional de autonomía y dificultades para encontrar un trabajo conveniente) son mayoritarias en la población estudiada. Aún así, cabría considerar la hipótesis de que para los estudiantes la adopción de esta estrategia podría significar seguir apostando por el proyecto profesional construido hasta el momento, sin tener que correr riesgos excesivos.

Esta muestra de constancia parece particularmente adecuada para los que profesan valores de autonomía e investigación, ya que les permitiría la adquisición de mayores recursos personales (conocimientos y formación) y quizá también más señales en forma de título ante el mercado laboral, todo ello con el objetivo de acceder a trabajos con un fuerte componente de autonomía, o bien más específicamente en el ámbito de la investigación. En este último caso, la opción de continuar en la universidad podría ofrecer todavía más posibilidades de obtener un puesto de trabajo investigando.

\section{c) Aceptación de sacrificios}

- Positivo: autonomía, investigación; investigación-Derecho, investigaciónSalud.

- Negativo: ocio.

De cara a pronosticar la adopción de la estrategia de aceptar sacrificios a cambio de poder cumplir el propio proyecto profesional, hemos constatado que la percepción sobre la situación del mercado laboral parece no tener ninguna importancia. Este hecho nos lleva a atribuir a esta opción un significa- 
do estrictamente vinculado con la variable que informa sobre la robustez y orientación del perfil y, por tanto, sobre la determinación con la que el estudiante emprende el cumplimiento de su proyecto profesional, sean cuales sean las condiciones externas percibidas.

Así, como era de esperar, los estudiantes que se definen por el valor profesional de ocio se alejan claramente de esta opción. En cambio, los que suscriben el valor autonomía marcan su preferencia por esta reacción futura, lo cual contribuye a corroborar la existencia de un proyecto profesional definido acompañando a este valor. Éste es también el caso para los estudiantes vinculados al valor investigación. Resulta interesante aquí prestar atención a las dos áreas más afectadas por esta tendencia: Derecho y Salud. Se trata de áreas tradicionalmente muy orientadas a la profesión, pero también detectamos en ellas la presencia de estudiantes que tienen en cuenta los lazos existentes entre la profesión y la actividad científica y las actitudes de investigación; son precisamente estos estudiantes los más dispuestos dentro de estas áreas a invertir esfuerzos considerables con el objetivo de realizar su proyecto profesional.

\section{d) Creación de empresa propia}

- Positivo: sin dificultades; mando, autonomía, investigación; mando-sin dificultades, autonomía-sin dificultades, investigación-sin dificultades, investigación-dificultades correspondencia.

- Negativo: valores sociales; valores sociales-dificultades correspondencia.

Hemos considerado la estrategia de crear una empresa propia como la más emprendedora de entre todas la contempladas. En este sentido, obtenemos datos del todo coherentes cuando la actitud asertiva y optimista de los que prevén una inserción sin dificultades se pone también de manifiesto en una mayor disposición a adoptar esta estrategia. Esta influencia se repite cuando aparece la tendencia en estudiantes con valores ya muy afines a la adopción de esta reacción: mando, autonomía e investigación, perfiles quizá más propicios a arriesgar y manejarse en el mercado persiguiendo ciertos aspectos muy valorados del trabajo.

En cambio, los estudiantes que presentan valores sociales rechazan la adopción de esta estrategia, lo cual nos lleva a considerar este perfil que potencia los valores altruistas como alejado de los valores empresariales generales.

En definitiva, llegados a este punto, podemos afirmar que se han puesto de manifiesto influencias efectivas de las variables contempladas sobre la variable que pretendíamos explicar (las reacciones previstas ante dificultades), erigiéndose como conceptos importantes a tener en cuenta la asertividad, el optimismo, el pesimismo, la disposición a perder el perfil profesional y el recurso a estrategias alternativas. Y, subyacente a toda esta relación, encontramos la 
variable área de estudio, la cual define los límites de lo que es pensable y lo que no, por su idiosincrasia, quizá a partir de la propia epistemología, configuración de conocimientos, tradición, aplicabilidad, alcance profesional, etc.

\section{Conclusiones}

En este artículo hemos trabajado, en primer lugar, con una variable referida a diversos aspectos del trabajo que los estudiantes debían valorar según la importancia que les atribuyeran. El resumen de esta información ha dado lugar a diversos tipos de «valores profesionales» (valores sociales, ocio, mando, autonomía e investigación) que utilizamos como indicador de perfil profesional. La distribución de tales perfiles se ha mostrado relevante a la hora de diferenciar entre áreas de estudio, con lo que hemos podido apreciar la existencia de un ethos profesional propio de cada área que, en general, ha mostrado su potencia transfronteriza; aunque vale decir que en algunas ocasiones la región ha pasado por encima de las diferencias entre áreas.

En segundo lugar, nos hemos acercado a las suposiciones que los estudiantes efectuaban sobre su futuro proceso de inserción, en función de la percepción que tenían respecto de la situación del mercado laboral. También en esta variable es posible distinguir la influencia tanto del área de estudio como de la región de pertenencia lo que define las diferencias en las percepciones de los estudiantes. Así, podríamos resumir la tendencia de los estudiantes catalanes con una visión siempre más pesimista que el resto; los de Baden-Württemberg manifiestan expectativas mejores en las áreas de Economía, Ingeniería y Ciencias, y los de Rhône-Alpes prevén una inserción mejor que en los demás países para las áreas de Humanidades, Sociales, Derecho y Salud. Igualmente, se hace muy patente la visión más optimista por parte de los hombres ante las previsiones que realizan las mujeres.

En tercer lugar, el examen de las reacciones que los estudiantes prevén tener ante dificultades de inserción, ha puesto de manifiesto que el área de estudio, la región de pertenencia y el sexo son variables explicativas para tres de las posibles estrategias contempladas: aceptación de trabajos en no-correspondencia, aceptación de sacrificios y crear empresa propia. En cambio, la continuación de estudios es una reacción en la que básicamente una sola variable se conforma como variable explicativa: la región de pertenencia.

Por último, nos quedan por señalar las relaciones que efectivamente se han observado entre las tres variables anteriores. Recordemos que partíamos del esquema de explicación según el cual el perfil profesional, junto con la percepción de las condiciones de inserción, podían dar cuenta de la probabilidad diferencial de adoptar una u otra reacción ante posibles dificultades de inserción en el mercado laboral.

Pues bien, por lo que concierne a la variable de percepción del mercado laboral, hemos visto que sólo incide, por un lado, sobre la decisión de adoptar la peor de las estrategias, es decir, la que mediante la aceptación de un trabajo que no corresponda con los estudios cursados comporta una pérdida clara del 
proyecto profesional. Y, por otro lado, cuando se da una de las categorías de la variable, la de no prever dificultades de inserción, viene asociada con mayor probabilidad a la estrategia de crear una empresa propia, es decir, que una visión optimista hace aumentar la probabilidad de adoptar una reacción más arriesgada ante posibles dificultades.

En cambio, la variable que recoge los valores profesionales se ha manifestado con una capacidad explicativa importante (siempre manteniéndonos alerta de la influencia indirecta que ejerce el área de estudio, que hemos mantenido constante). De manera que han quedado asociadas la estrategia que conlleva una pérdida clara de perfil profesional con el valor profesional ocio; estrategias múltiples, siempre asertivas respecto del proyecto profesional, con los valores profesionales de autonomía e investigación; la creación de empresa con el valor mando, y los valores sociales se asocian en negativo con la creación de empresa, mientras que favorecen la estrategia de continuar estudiando.

Con ello, se pone de manifiesto que unos valores profesionales predisponen más que otros a la adopción de ciertas estrategias, aunque también algunas veces hemos visto cómo se mezclan con la percepción que los estudiantes tienen de su futura inserción: es el caso de la aceptación del infortunio que supone la pérdida del proyecto profesional ante la previsión de muchas dificultades de inserción; o, en el caso contrario, la aserción que supone lanzarse a crear una empresa propia reforzando una visión más optimista del mercado.

En definitiva, merece la pena recalcar que la percepción del futuro proceso de inserción (condiciones externas) parece afectar a las estrategias futuras de forma menos fundamental de lo que lo hacen los valores desarrollados durante una larga vida de estudio, con un alto grado de esfuerzo ya invertido sobre el propio proyecto profesional.

\section{Bibliografía}

BARGEL, T. (2001). «Concepts théoriques pour le développement d'un instrument d'enquête d'étudiants». Groupe de travail chargé de recherches sur les universités / Université de Constance.

Barnett, R. (2000). «Supercomplexity and the Curriculum». Studies in Higher Education, vol. 25, n. ${ }^{\circ}$ 3, p. 255-265.

CARABAÑA, J. (1991). «Por una evaluación sistemática de los planes de estudio». En III Jornadas Nacionales de Didáctica Universitaria. Universidad de Las Palmas.

ERAUt, M. (1994). Developing professional knowledge and competence. Londres: The Falmer Press.

GALLAGHER, M. (2002). «Favoriser la réactivité des universités: les incitations visant les étudiants dans l'enseignement supérieur australien». En Répondre aux attentes des étudiants. París: OCDE.

Hadis, Ch.; Fernex, A.; Lima, L. (2003). Les étudiants de la Région Rhône-Alpes face a leurs études. LSE, UPMF Grenoble (edición policopiada).

Herzberg, F.; Mauser, B.; SNyderman, B. (1959). The Motivation to Work. Nueva York: Willey. 
JAMES, R. (2002). «L'évolution des attentes des étudiants de l'enseignement supérieur et les conséquences de leur manque de réalisme». En Répondre aux attentes des étudiants. París: OCDE.

Maravall, J.M. (1987). «El desarrollo de la reforma universitaria». En CONSEJO DE UNIVERSIDADES. El desarrollo de la reforma universitaria. Actas y Simposios. Madrid: Consejo de Universidades, Secretaría General.

MASJUAN, J.M. (2005). «Progresos en los aprendizajes, características de los estudios y motivaciones de los estudiantes». Papers (este ejemplar).

Masjuan, J.M.; Troiano, H.; Molins, C. (2003). Els estudiants universitaris davant dels seus estudis $i$ el futur professional. Aqu Catalunya. (edición policopiada).

SÁNCHEZ Ferrer, L. (1996). Politicas de reforma universitaria en España: 1983-1993. Madrid: Centro de Estudios Avanzados en Ciencias Sociales. Tesis Doctorales, 12. 